\title{
Are data from general practices suitable for survival analyses in the field of breast cancer? A retrospective study conducted in the United Kingdom, France and Germany
}

\author{
LOUIS JACOB ${ }^{1}$, MATTHIAS KALDER ${ }^{2}$, GABRIELE HAAS $^{3}$ and KAREL KOSTEV ${ }^{4}$ \\ ${ }^{1}$ Faculty of Medicine, University of Versailles Saint-Quentin-en-Yvelines, 78180 Montigny-le-Bretonneux, France; \\ ${ }^{2}$ Department of Gynecology and Obstetrics, Philipps University of Marburg, D-35043 Marburg; \\ Departments of ${ }^{3}$ Oncology and ${ }^{4}$ Epidemiology, IQVIA, D-60549 Frankfurt, Germany
}

Received February 25, 2019; Accepted May 16, 2019

DOI: $10.3892 / \mathrm{mco} .2019 .1874$

\begin{abstract}
The aim of the present study was to investigate the suitability of data obtained from general practices in the UK, France, and Germany for survival analyses in the field of breast cancer (BC). This study included women diagnosed with $\mathrm{BC}$ between 2004 and 2008 in 416, 322 and 210 general practices in the UK $(n=4,085)$, France $(n=1,198)$ and Germany $(n=2,934)$, respectively. The outcomes of the study were the mean duration of follow-up in years and the proportion of participants followed for at least 5 years. The mean duration of follow-up was 7.5-9.6 years in the UK, 7.4-8.8 years in France and 6.3-8.5 years in Germany. The proportion of patients followed for at least 5 years was $80-91 \%$ in the UK, 68-78\% in France, and 55-76\% in Germany. The data obtained in general practices in the UK appeared to be more suitable for survival analyses in the field of $\mathrm{BC}$ when compared with those obtained in France and Germany.
\end{abstract}

\section{Introduction}

Breast cancer (BC) is the most frequent cancer in women and the second most common cancer in the general population worldwide, with approximately two million new cases in 2018 (1). BC mortality rates have recently decreased in high-income countries, and this declining trend is likely explained by the early detection and improved treatment of this cancer (2). The average 5-year survival rate for women with invasive BC is about $90 \%$, and, since BC is considered a chronic condition, and since this disorder has a substantial

Correspondence to: Professor Karel Kostev, Department of Epidemiology, IQVIA, Unterschweinstiege 2-14, D-60549 Frankfurt, Germany

E-mail:kkostev@de.imshealth.com

Key words: suitability of data, general practice, breast cancer, survival analyses, retrospective study impact on health $(3,4)$, the long-term follow-up of patients with $\mathrm{BC}$ is of particular importance.

The management of BC survivors is multidisciplinary and involves a wide range of health professionals (e.g., physicians, nurses, psychologists). The specialist in charge of BC management can be either the oncologist or the gynecologist, depending on the country in question (5-7). Although the specific role of general practitioners (GPs) in the care of individuals with $B C$ is not well defined, the importance of GPs has increased steadily in recent years. A cross-sectional questionnaire study including 317 GPs from Norway reported that 17 and $62 \%$ of them provided follow-up care to women with BC on a regular basis less than and more than five years after treatment respectively (8). More recently, a survey of 740 cancer patients showed that a substantial proportion of them visited GP practices for several reasons (e.g., blood test, complaints and side effects, comorbidities) during their cancer therapy, and that $54 \%$ of participants reported being satisfied with their primary care physician (9). These studies have advanced our knowledge about the role played by GPs in the management of people affected by BC.

Epidemiological studies using survival analyses may benefit from data obtained from GP practices. However, in order to be methodologically valid, these studies require the survival time to be similar to the follow-up time. Unfortunately, little is known about the duration of follow-up in BC patients in GP practices after the diagnosis of cancer, and it is possible that $\mathrm{BC}$ survivors change doctors more frequently than people with other conditions (e.g., osteoporosis, diabetes, hypertension). This may be due to several reasons, such as the primary care physician's lack of experience with cancer or his/her lack of empathy $(10,11)$.

Therefore, the goal of this study was to investigate the suitability of data obtained from general practices in the UK, France, and Germany for survival analyses in the field of BC.

\section{Materials and methods}

Database. This retrospective study was based on data from the Disease Analyzer database (IQVIA). This database compiles demographic, clinical, and pharmaceutical data obtained in 
an anonymous format from the computer systems used in clinical practices (2). The quality and accuracy of the data (e.g., diagnoses, drug prescriptions) are regularly assessed by IQVIA. Using prescription statistics for several drugs and age groups for several diagnoses, the Disease Analyzer database was shown to be representative of clinical practices in Germany (12). Finally, this database has already been used for several studies focusing on BC $(13,14)$.

Patients and outcomes. This study included data obtained from women diagnosed for the first time with BC (International Classification of Diseases, 10th revision: C50) between 2004 and 2008 in 416, 322, and 210 GP practices in the UK, France, and Germany respectively (index year). Women were selected only if they had not been diagnosed with another cancer (C00-C99) (Fig. 1).

The outcomes of the study were the mean duration of follow-up in years and the proportion of women with BC followed for at least five years. These outcomes were studied in different age subgroups (i.e., $\leq 50,51-60,61-70,>70$ years).

Statistical analysis. The present retrospective study used descriptive statistics only. Differences in the mean follow-up time between the three countries were tested using Kruskal-Wallis tests (data were not normally distributed). $\mathrm{P}<0.05$ was considered to indicate a statistically significant difference. All analyses were carried out using SAS 9.4 (SAS Institute, Cary, USA).

\section{Results}

The study included 4,085 women from the UK, 1,198 from France, and 2,934 from Germany (Table I). The mean age was 60.0 years ( $\mathrm{SD}=4.7$ years) in the UK, 61.7 years $(\mathrm{SD}=12.6$ years) in France and 62.5 years $(\mathrm{SD}=12.4$ years) in Germany. The mean duration of follow-up was 7.5-9.6 years in the UK, 7.4-8.8 years in France and 6.3-8.5 years in Germany $(\mathrm{P}<0.03)$ (Fig. 2). The proportion of patients followed for at least five years was $80-91 \%$ in the UK, 68-78\% in France, and $55-76 \%$ in Germany (Fig. 3). Women aged $>70$ had the shortest duration of follow-up.

\section{Discussion}

This is the first study investigating the suitability of data obtained in general practices for survival analyses in the field of BC. We found that a substantial proportion of participants with this cancer were followed for less than five years in France and Germany. Therefore, the data obtained from general practices in these two countries may not be appropriate for survival analyses in the context of BC. By contrast, more than $80 \%$ of $\mathrm{BC}$ patients were followed for at least five years in the UK.

Survival analyses, also known as time-to-event analyses, are a branch of statistics focusing on data where the dependent variable is the time until the occurrence of an event of interest (e.g., death, metastasis, depression). One major characteristic of survival analyses is that data are usually censored, meaning that the information about the survival time of some individuals is incomplete (15). Although there are several statistical methods that take censoring into account, censored
Table I. Baseline characteristics of study patients.

\begin{tabular}{lccc}
\hline Variables & UK & France & Germany \\
\hline Total n & 4,085 & 1,198 & 2,934 \\
Age in years, & $60.0(4.7)$ & $61.7(12.6)$ & $62.5(12.4)$ \\
mean (SD) & & & \\
Age, years & & & \\
550 & 27.8 & 22.4 & 18.8 \\
$51-60$ & 26.2 & 26.4 & 22.9 \\
$61-70$ & 21.9 & 23.2 & 30.9 \\
$>70$ & 24.1 & 28.0 & 27.5 \\
Year of initial diagnosis & & & \\
(index year) & & & \\
2004 & 19.7 & 12.8 & 23.2 \\
2005 & 19.9 & 18.8 & 20.2 \\
2006 & 20.5 & 22.8 & 19.2 \\
2007 & 19.2 & 22.8 & 18.8 \\
2008 & 20.7 & 22.8 & 18.6 \\
\hline
\end{tabular}

SD, standard deviation.

samples can undermine the findings of survival analyses, and one should bear in mind that not all data are suitable for this type of analysis.

There are several hypotheses that could explain why the mean duration of follow-up was relatively short and the proportion of participants followed for more than five years relatively low in general practices in Germany. For example, a recent study including 464 Danish GPs reported substantial variation in empathy between physicians, and this variation was significantly associated with several factors, such as the physician-patient relationship and physicians' interactions with their colleagues (11). Since the diagnosis of BC has major psychological effects (16), women with BC may be more likely than women with other chronic conditions (e.g., osteoporosis, hypertension, diabetes) to change doctors when they identify a lack of empathy in their physician. Another survey of primary care physicians showed that lack of formal training with regard to cancer was a problem for almost half of the responders (47\%) when treating cancer survivors (10). Therefore, a lack of experience with BC may sometimes motivate general practitioners to refer women suffering from this condition to other primary care physicians or specialists (e.g., gynecologists, oncologists). In addition, the occurrence of complications requiring specialized care may explain the discrepancy between the proportion of participants with $\mathrm{BC}$ who were followed for at least five years in general practices in both Germany and France (i.e. $<80 \%$ ) and the proportion of $\mathrm{BC}$ survivors five years after cancer diagnosis (i.e. >80\%) (17). For example, a prospective study of Canadian women with BC estimated that the prevalence of bone metastases is around $6.5 \%$ five years after BC diagnosis (18), while heart failure and cardiomyopathy are frequent after adjuvant therapy for this cancer (19).

Our findings indicate that, although the data obtained from general practices are important for the improvement 

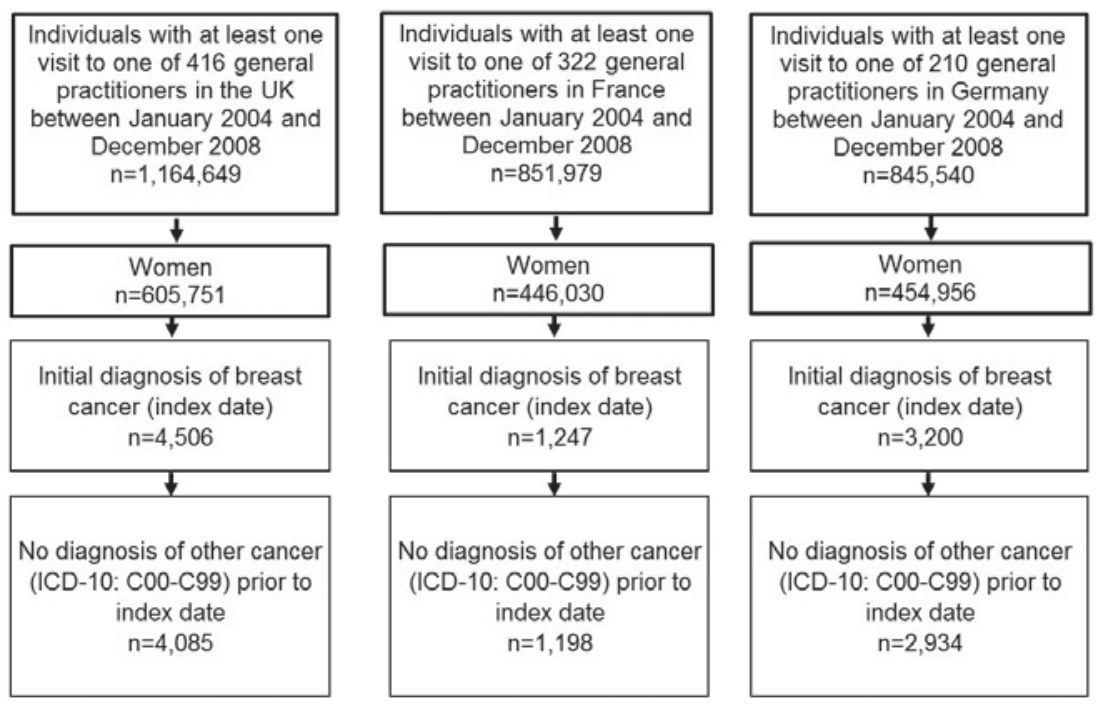

Figure 1. Flowchart presenting the methodology involved in the selection of study patients.

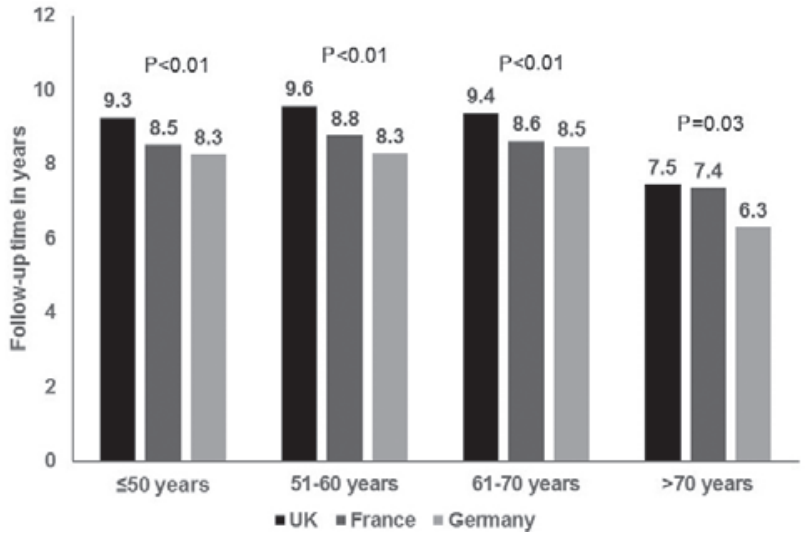

Figure 2. Mean duration of follow-up in patients with BC in the UK, France and Germany. BC, breast cancer.

of our understanding of the epidemiology of BC, one major point should be considered before conducting survival analyses using these data. Researchers should ensure that the mean follow-up of patients is sufficient and that it is not vastly different from the mean survival time. If this is not the case, it may affect the validity of studies with long-term outcomes, such as mortality at five years or metastases at 10 years. Since a substantial proportion of the individuals censored may have simply changed doctors, using an unique personal identification number for each patient may help overcome this issue in the future (20). Finally, further research is needed to gain a better understanding of the factors that may impact the follow-up of BC survivors in general practices in Europe and other areas of the world.

The major strengths of this study are the use of data from three countries and the number of patients available for analysis. However, the results of this study should be interpreted in light of several limitations. Firstly, if a participant visited another GP, this visit would not have been documented in the database and this participant would have been censored. Secondly, there was no information

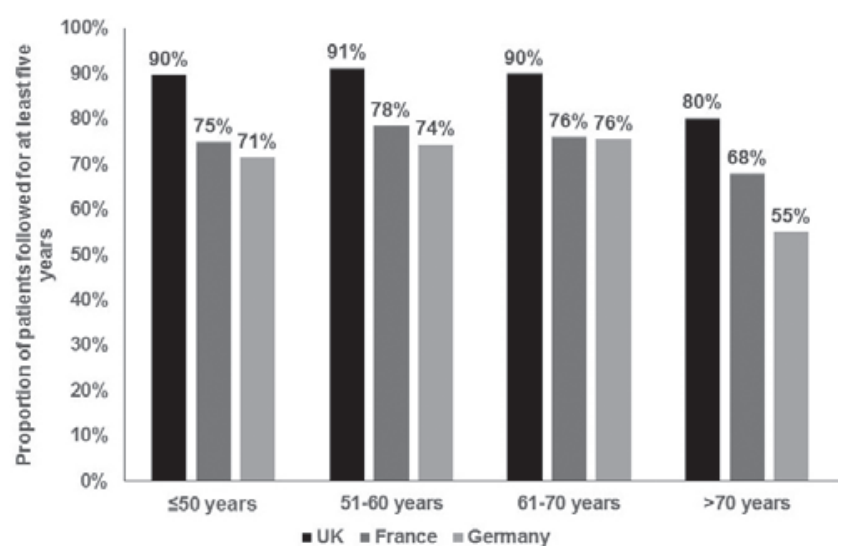

Figure 3. Proportion of patients with BC in the UK, France and Germany followed for at least 5 years. $\mathrm{BC}$, breast cancer.

on the factors that potentially impacted the follow-up of women with BC (e.g., lack of empathy displayed by the primary care physician, a physician's lack of experience with cancer, development of complications). Finally, it is possible that there were differences in terms of data completeness between the UK, France, and Germany, which could explain the discrepancy in the findings that were observed between these three countries.

Overall, the data obtained from general practices in France and Germany may be inappropriate for survival analyses in the field of BC. Future studies are needed to corroborate or refute the present findings and to investigate the potential factors impacting the follow-up of women with $\mathrm{BC}$ in general practices.

\section{Acknowledgements}

Not applicable.

\section{Funding}

No funding was received. 


\section{Availability of data and materials}

The datasets used and/or analyzed during the present study are available from the corresponding author on reasonable request.

\section{Authors' contributions}

LJ designed the study, interpreted the data, and drafted and revised the manuscript. KK conceived and designed the study, performed statistical analysis, interpreted the data, and revised the manuscript. MK and GH interpreted the data, and revised the manuscript. All authors have read and approved the final manuscript.

\section{Ethics approval and consent to participate}

Not applicable.

\section{Patient consent for publication}

Not applicable.

\section{Competing interests}

The authors declare that they have no competing interests.

\section{References}

1. World cancer research fund. Breast cancer statistics. https:// www.wcrf.org/dietandcancer/cancer-trends/breast-cancer-statistics, 2018.

2. Torre LA, Siegel RL, Ward EM and Jemal A: Global cancer incidence and mortality rates and trends-an update. Cancer Epidemiol Biomarkers Prev 25: 16-27, 2016.

3. Tian Y, Schofield PE, Gough K and Mann GB: Profile and predictors of long-term morbidity in breast cancer survivors. Ann Surg Oncol 20: 3453-3460, 2013.

4. Jacob L, Kalder M and Kostev K: Incidence of depression and anxiety among women newly diagnosed with breast or genital organ cancer in Germany. Psychooncology 26: 1535-1540, 2017.

5. Lebeau M, Mathoulin-Pélissier S, Bellera C, Tunon-de-Lara C, Daban A, Lipinski F, Jaubert D, Ingrand P and Migeot V; REPERES Group: Breast cancer care compared with clinica guidelines: An observational study in France. BMC Public Health 11: 45, 2011.
6. Wallwiener M, Brucker SY and Wallwiener D; Steering Committee: Multidisciplinary breast centres in Germany: A review and update of quality assurance through benchmarking and certification. Arch Gynecol Obstet 285: 1671-1683, 2012.

7. Zollman C, Walther A, Seers HE, Jolliffe RC and Polley MJ: Integrative whole-person oncology care in the UK. J Natl Cancer Inst Monogr 2017, 2017.

8. Fidjeland HL, Brekke M and Vistad I: General practitioners' attitudes toward follow-up after cancer treatment: A cross-sectional questionnaire study. Scand J Prim Health Care 33: 223-232, 2015.

9. Lang V, Walter S, Fessler J, Koester MJ, Ruetters D and Huebner J: The role of the general practitioner in cancer care: A survey of the patients' perspective. J Cancer Res Clin Oncol 143: 895-904, 2017.

10. Bober SL, Recklitis CJ, Campbell EG, Park ER, Kutner JS, Najita JS and Diller L: Caring for cancer survivors: A survey of primary care physicians. Cancer 115 (18 Suppl): S4409-S4418, 2009.

11. Charles JA, Ahnfeldt-Mollerup P, Søndergaard J and Kristensen T: Empathy variation in general practice: A survey among general practitioners in Denmark. Int J Environ Res Public Health 15: pii: E433, 2018

12. Rathmann W, Bongaerts B, Carius H-J, Kruppert S and Kostev K: Basic characteristics and representativeness of the German disease analyzer database. Int J Clin Pharmacol Ther 56: 459-466, 2018.

13. Kostev K, Jacob L and Kalder M: Risk of depression, anxiety, and adjustment disorders in women with a suspected but unconfirmed diagnosis of breast or genital organ cancer in Germany. Cancer Causes Control 28: 1021-1026, 2017.

14. Jacob L, Scholten PC, Kostev K and Kalder M: Association between sleep disorders and the presence of breast cancer metastases in gynecological practices in Germany: A case-control study of 11,412 women. Breast Cancer Res Treat 171: 443-448, 2018.

15. Leung KM, Elashoff RM and Afifi AA: Censoring issues in survival analysis. Annu Rev Public Health 18: 83-104, 1997.

16. Glanz K and Lerman C: Psychosocial impact of breast cancer: A critical review. Ann Behav Med 14: 204-212, 1992.

17. Holleczek B, Jansen L and Brenner H: Breast cancer survival in Germany: A population-based high resolution study from Saarland. PLoS One 8: e70680, 2013.

18. Liede A, Jerzak KJ, Hernandez RK, Wade SW, Sun P and Narod SA: The incidence of bone metastasis after early-stage breast cancer in Canada. Breast Cancer Res Treat 156: 587-595, 2016.

19. Chen J, Long JB, Hurria A, Owosu C, Steingart RM and Gross CP: Incidence of heart failure or cardiomyopathy after adjuvant trastuzumab therapy for breast cancer. J Am Coll Cardiol 60: 2504-2512, 2012.

20. Ludvigsson JF, Otterblad-Olausson P, Pettersson BU and Ekbom A: The Swedish personal identity number: Possibilities and pitfalls in healthcare and medical research. Eur J Epidemiol 24: 659-667, 2009. 